\title{
Investigation of Factors Affecting Investment in Textile Industry and the Influence of Development of this Industry on National Employment
}

\author{
Hamed Zakizadeh \\ Department of Business Management, Faculty of Management, Central Tehran Branch, \\ Islamic Azad University, Tehran, Iran \\ Mansoureh Aligholi \\ Department of Business Management, Faculty of Management, Central Tehran Branch, \\ Islamic Azad University, Tehran, Iran \\ Email: man.aligholi@iauctb.ac.ir
}

\section{Doi:10.5901/mjss.2015.v6n3s2p703}

\begin{abstract}
The present research tries to investigate factors affecting investment in textile industry and the influence of development of this industry on national Iranian employment. The conceptual model of the research studies variables like import, export, sanctions and risk as independent variables which influence investment in textile industry and national employment. This is an applied descriptive (survey) study. The questionnaire used for data collection was a standard questionnaire with 24 items which were based on Likert scale. Since the population number was 9800 , we selected 270 people as sample size. Validity of the research was verified by confirmatory factor analysis and based on the ideas of experts. Cronbach's alpha was used for determination of reliability of the questionnaire. Structural equations modeling technique (in LISREL software) was used for data analysis. Results showed that import, export and risk have significant influences on investment in textile industry but sanction does not have any significant influence on investment. Therefore, sanction variable was eliminated. Finally, the fifth hypothesis of the research regarding the significant influence of investment in textile industry on employment was accepted.
\end{abstract}

Keywords: investment, import, employment, textile industry and risk

\section{Introduction}

The present era is full of unpredictable transformations and companies are confronted with the harshest competitive conditions due to factors like unclear borders of markets, fragmentation of markets, short products lifecycles, and rapid changes in customers' purchase desires and awareness of customers (Tavanazadeh and Aligholi, 2014). Managers should have special features, abilities and potential competencies, knowledge, experience and socio-communicational skills in order to manage organizations effectively. Managers should start from targets and pay attention to their resources and especially human resources (Rahnama et al, 2011). Economic development is a national and public desire for all countries. Seeking for perfection is a characteristic of human beings. This is expressed in innovation, creativity and inventions and these in part help human dominate the nature. Therefore, social and economic dynamism depends on flourishing of potential forces in "human" and all actions which help free human thought from ignorance also help change material environment. therefore, growth is a natural matter but acceleration in growth or slowness in motion and retardation are affected by the conditions and system of government. If a society spends a period of time in recession, it must look for barriers against motivations. In contrast, if a nation experiences a growth rate beyond a natural trend, we must look for factors which have promoted motivations and stimulants of creativity and innovation. In Iran, injection of petroleum export income (income obtained from a trend other than national production and creation of added value)into national economy stopped self-sufficient production capacities. Therefore, national economy and industries became dependent and caught in a vicious cycle. Further, development of production depends on foreign currency and acquisition of currency depends on increasing national production (Motavasseli, 2003). 


\section{Theoretical Framework}

\subsection{Textile industry}

Completion of textile products refers to a collection of operations conducted on fabric aimed at increasing its quality. In production of textile products, completion refers to all stages experienced by thread, fabric and Jersey in order to have a better appearance, flawless efficiency and soft touch. Completion operation is conducted after production of textile product (SahiZadehAbiyaneh, 1996).

\subsection{Textile industry}

Textile industry is responsible for production of different types of textiles including different types of clothes, floor mats like carpets and mattresses and other textiles used in other industries. This industry includes different sectors like spinning and knitting factories, production of carpet by machines and factories which are supplementary of these products like dyeing and printing and artificial الياف production factories like Nylon and polypropylene.

\subsection{Capital}

Capital is an important element in production in capitalism economy. It refers to a property which brings profits and is expressed based on money. Usually, the term capital is synonymous to capital goods. Sometimes, capital is called "capital money" or "property capital". By money in the form of capital, we mean a part of capital which is reserved in the form of money or bank deposit and property capital is that share of capital which is kept in the form of title deed like stocks and bonds (Farhang, 1992).

\subsection{Investment}

It refers to the flow of expenditures which is used for increasing or stabilizing real capital volume. In fact, a more precise definition involves description of the above definition: investment means a flow of costs dedicated to plans for production of products which are not going to be used immediately. These investment plans may be in the form of increasing material capital and human capital or inventory (Najafzadeh, 2009).

For short, investment is an increase resulted from economic wealth at a particular time. Investment flow involves production of new capital goods and increase in real assets like inventory.

In many cases, investment refers to formation of capital. Formation of capital means when a society does not dedicate all its present productive activities to immediate consumption desires and requirements but a part of the activities is spent on production of capital goods like instruments and machinery, transportation equipment, workshops, equipment and all different forms of capital which are able to increase the influence of society's productive force (Shahsavari, 2004). Human capital is a vital kind of capital. The present era is the arena of competition over resources and capitals. Large industrial countries pay attention to productivityand have made innovations and inventions. Access to such innovations depends on entrepreneurship (Shafae et al, 2012). Considering the fact that in economic theories, by investment we mean "purchase of production equipment by money capital and for additional production", it is necessary to mention that special economic schools have provided different definitions based on their special insights. For instance, based upon neoclassic theory, investment is a kind of comparison between opportunity costs of two types of values. Accessible current value (which can have other opportunity cost except entering investment process) and future value which will be acquired via production process (Shahsavari, 2004).

\subsection{Export}

It refers to selling services and products of a country to other countries in exchange for receiving products, services, currency, gold, settlement of debts or in order to do a non-return contribution, repairmen, completion or participation in fairs. The present era is full of unpredictable transformations and companies are confronted with the harshest competitive conditions due to factors like unclear borders of markets, fragmentation of markets, short products lifecycles, and rapid changes in customers' purchase desires and awareness of customers (Vazifehdoost, Vaezi\&Tavanazadeh, 2014). Export is divided into two categories:

a) visible export (product): it includes raw materials, products, machinery and other products which are exported 
abroad physically.

b) invisible export: it includes services like insurance, banking, transportation, payment of interest, EPS, tourism and services provided by citizens abroad (Nahavandiyan, 1994).

\subsection{Import}

In general, products import means purchase, exchange or receiving services and products from other countries which is done after observing customs formality and observation of import regulations. Import has many different types like definite import, presented products import and so on. Definite products import is a customs procedure in which the imported product(s) is released after observation of all customs formality and after paying customs duties.

\subsection{Risk}

In general, risk means uncertainty and it is a doubt which comes to one's mind regarding the result of an action. On the other hand, risk is defined as chance for loss or possibility of loss. Risk and return are accompanying concepts in finance and investment and they cannot be separated from each other because investment decisions are always made based on relationship between risk and return on investment. Investors always consider risk in their decision-makings. Risk is divided into systematic and non-systematic risks. This kind of classification is very important in portfolio management and investment analyses (Jones, 2005).

\subsection{Risk importance}

Risk is one of the main factors in making decisions regarding investment, financial markets and different types of economic activities. In most economic books, main production inputs are work, land and capital. However, these three factors are actually necessary factors for production but the adequate condition in production process is nothing but risk factor. In other words, if the three factors are there but the producer does not accept the possible needs of this process, the production process will never start. Therefore, risk factor is considered as the fourth factor in production process (MesbahiMoghaddam and Safari, 2009). For decades, a company's value was measured based on its equipment, properties, tangible assets and factories. However, it is now believed that the real value of a company is somewhere in potential consumers' minds (Heidarzadeh et al, 2011). Therefore, investments are accompanied by hard conditions and risks and they must be analyzed before investment.

\section{Different types of Risks}

1. Financial risk:

* Currency risk: currency risk means possibility for loss in a non-coverage situation, which occurs as a result of increasing or decreasing the value of a foreign currency. Using the present advanced models (like value exposed to risk), this kind of risks can be controlled for prediction and measurement of risk and use of present financial instruments (like derivative instruments: such as currency swap, futures on currency value). This reduces bank's currency risk.

* Price risk: this risk is resulted from variations and drastic changes in the price of assets and deposits in banks.

* interest rate risk: the probability of reduction in the value of an interest-bearing asset (like bank loan) as a result of variations in interest rates in the market is called interest rate risk. Change in assets values as a result of variations in interest rate is a function of change in the rate and maturity of assets. Long-term loans with fixed interest rates which are provided by financial institutes are a kind of ignorance of this kind of risk. The most obvious method for controlling this kind of risk is making the rate of banking loans interests and deposits returns rate variable.

* Liquidity risk: liquidity risk is the main risk in the capital market and means the risk for shortage of liquidity for satisfying current costs and depositors demands in banks. This risk indicates that a bank does not have enough short-term salable assets or cash resources in order to be able to repay borrowers and depositors debts. This risk is resulted from three factors: inability to implement short-term financial commitments, inability to provide short-term financial resources when necessary and inability to do short- 
term finance. Within the recent years, many banks have become bankrupt because of ignorance of liquidity risk and mistrust of depositors and investors in the bank's ability to repay their debts.

* Market risk: variations in different rates in the market like inflation rate, currency rate and so on influence the price of assets and liabilities and their costs. Failure to predict such variations are called market risk (ShayanArani, 2001).

* Credit risk: credit risk resulted from granting commercial credits is the main risk in banking activities. In order to give out loans, we must determine the degree of validity and the power for repaying the principal and interest of loans by borrowers. The probability for not returning the principal and interest of loans is called credit risk. This can be resulted from reduction in repayment power and absence of proper planning for credit risk.

* Exchange Rate Risk: conversion of a currency (primary currency) into another currency (secondary currency) and investing the new currency (secondary) in order to be benefited from higher ROls will be followed by risk of conversion rate till maturity to the primary currency for coupon and principal. If the conversion rate of the secondary currency at reception time of coupon and principal in periods till maturity is reduced with respect to the primary currency, there is a possibility for not becoming benefited from the difference between two rates and the ROI of a part of the capital will be also sacrificed.

* Operational risk: operational risk can occur as a result of failure in personnel and individuals' efficiency, technology and working trend.

* Inflation rate: this refers to risks regarding investor's loss due to reduction in money value (inflation).

* Inflation refers to a situation in economy in which the general level of prices increases continuously and significantly and in an irreversible manner.

* Inflation risk: it is also known as purchase power risk. When the general level of prices increases, this means that a lower amount of products can be bought by means of a constant amount of assets. In other

Employment words, inflation means reduction in financial assets power with respect to real assets.

It means entrepreneurship. In a society which suffers from unemployment, all thoughts are directed at creating new jobs. Although creation of new jobs and entrepreneurship are both valuable and related but they are not the same (creation of new jobs can be one of the results of entrepreneurship). Therefore, these two terms have the following differences:

1. an entrepreneur creates a new job but a job creator absorbs workforce and completes the capacity for the created job.

2. entrepreneurship regards mostly to the private sector but creation of jobs can be also formed in the public sector. This is because the main feature of an entrepreneur is acceptance of risk and provision of finance in exchange for high benefit. In public sector, however, investment and risk will not be necessarily followed by high income and profitability. The government can facilitate and encourage entrepreneurship.

3. entrepreneurship is the supply of new products or services in terms of place or time. However, creation of jobs is not necessarily accompanied by innovation.

4. entrepreneurship is the understanding and application of the present or future opportunities in the market which benefits both the entrepreneur and society while creation of jobs may be directed at society only.

5. creation of jobs contributes to distribution of the present wealth but entrepreneur creates a source of new wealth (creates value).

6. an entrepreneur collects a set of human and physical resources so that the new set has a higher value than the previous. This is while creation of jobs is not always accompanied by productivity (Mashhad Ferdosi University site).

\section{Research Model}

The conceptual model of the present research is based upon research literature. The conceptual model of the research was designed to understand and predict (determine) the effective factors. In the present research, the amount of investment in textile industry and its dimensions (export, import, sanction and investment risk) were considered as independent variables and creation of new jobs was assumed to be the dependent variable. 


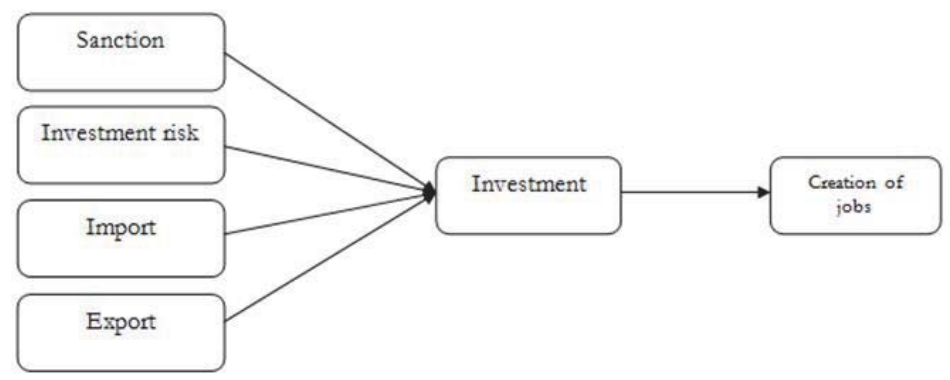

Figure 1: Research conceptual model

\section{Research Hypotheses}

Hypothesis 1: sanction has a significant influence on investment in textile industry.

Hypothesis 2: investment risk has a significant influence on investment in textile industry.

Hypothesis 3: export has a significant influence on investment in textile industry.

Hypothesis 4: import has a significant influence on investment in textile industry.

Hypothesis 5: investment in textile industry has a significant influence on creation of new jobs in this industry.

\section{Research Methodology}

The present research aims to investigate factors affecting investment in textile industry and the influence of development of this industrial sector on Iranian employment and job creation. This is an applied research in terms of goal. In terms of data collection, it is a descriptive research. Further, the research is a correlation study in term of data analysis. Data were analyzed by means of structural equations modeling.

\section{Statistical Population and Sample}

Statistical population of this research included all managers in Iranian textile industry. They were 9800 people in number. 285 managers were selected as sample members by means of Krejcie\& Morgan table. 300 questionnaires were distributed and 270 complete questionnaires were returned to be analyzed.

\section{Data Collection Instrument}

A questionnaire was used for collection of data. the questions were based on 5-point Likert scale. 30 questionnaires were distributed among managers as a pretest. Cronbach's alpha was used for reliability measurement. Results showed that Cronbach's alpha coefficients for all variables and total questionnaire were greater than 0.7 (table 1 indicates Cronbach's alpha coefficients for variables and total questionnaire). On the other hand, content validity of the research questionnaire was verified by professors. Therefore, the questionnaire had enough reliability and validity to be distributed among statistical population members.

Table 1: Cronbach's alpha coefficients

\begin{tabular}{|c|c|}
\hline Research variables & Calculated Cronbach's alpha \\
\hline investment & 0.890 \\
\hline Creation of jobs & 0.913 \\
\hline sanction & 0.754 \\
\hline Investment risk & 0.882 \\
\hline export & 0.865 \\
\hline import & 0.884 \\
\hline Total questionnaire & 0.802 \\
\hline
\end{tabular}

Table 2 indicates demographic information regarding respondents. 
Table 2: Research demographic variables

\begin{tabular}{|c|c|l|c|}
\hline Frequency Percentage & Frequency & Dimensions & Variable \\
\hline 76 & 204 & Male & Gender \\
24 & 66 & Female & \\
\hline 31.1 & 84 & $20-30$ & \multirow{2}{*}{ Age } \\
47 & 127 & $31-40$ & \\
11.5 & 31 & $41-50$ & \\
10.4 & 28 & 51 and above & Education \\
\hline 24.1 & 65 & High school degree & \\
16.3 & 44 & Associate's degree & \\
44.1 & 119 & Bachelor degree & Master degree and above \\
15.5 & 42 & M &
\end{tabular}

\section{Data Analyses}

Structural equations modeling and LISREL software were used for testing the research hypotheses. In structural equations modeling technique, we try to test relationships among latent variables (Kalantari, 2009). Structural equations modeling technique is a statistical modeling technique. This method embraces other techniques like multivariate regression, factor analysis and path analysis. Its main concentration is on latent variables which are defined by measurable indices and obvious variables. the important point in structural equations modeling is investigation of fitness of research model for investigation of relationships among variables. this is done via fitness indices which are provided by final output of LISREL.

Table 3: Fit indices

\begin{tabular}{lcl}
\hline Allowable limit & Calculated value & Index name \\
\hline Below 3 & 2.328 & $\frac{\chi^{2}}{d f}$ ) kai-squared on df( \\
Above 0.9 & 0.85 & GFI)goodness of fit index( \\
& & RMSEA)root mean square error approximation ( \\
Below 0.1 & 0.073 & CFI) comparative fit index( \\
Above 0.9 & 0.95 & AGFI)adjusted goodness of fit index( \\
Above 0.9 & 0.81 & NFI)normalized fit index( \\
Above 0.9 & 0.97 &
\end{tabular}

As it can be seen in table 2, all fit indices including ratio of Kai-squared on degree of freedom (2.328), p index(0.000), root mean square error approximation (RMSEA=0.073), comparative fit index $(0.95)$ and normalized fit index $(0.97)$ are in allowable limit except for fit index and adjusted fit index. This shows that the model is fit enough. We used the results of calculations of LISREL software in two states of research model i.e. in significance state (figure 1) and research model in standard state (figure 2).

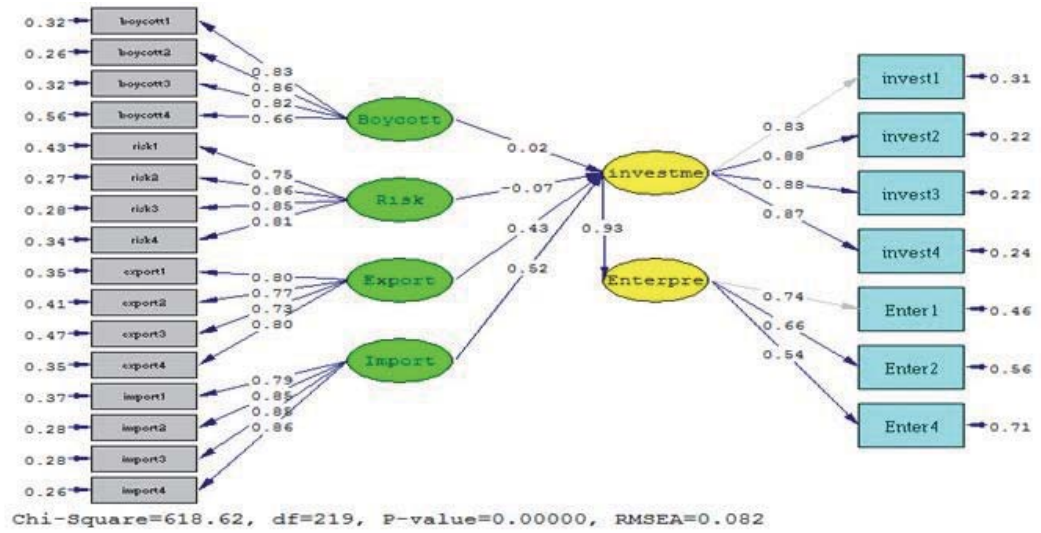

Figure 1: Model in significance state 


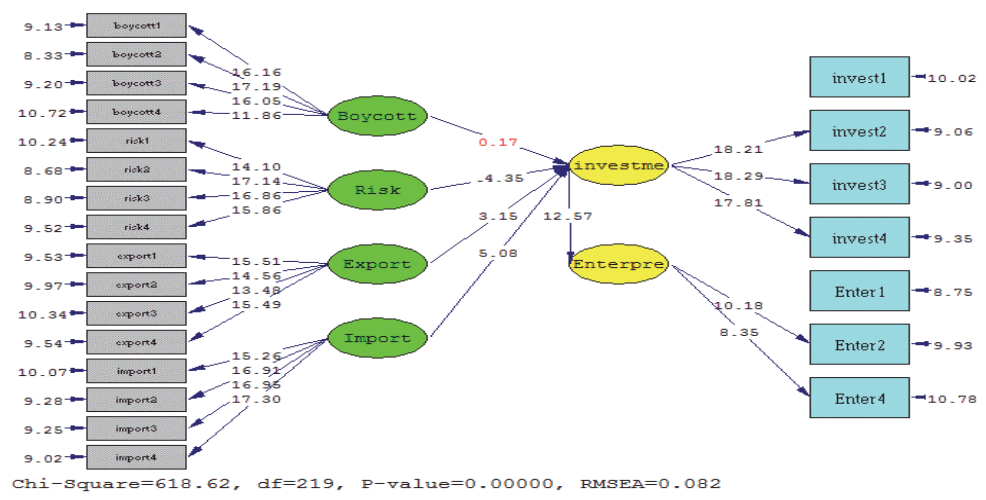

Figure 2: Model in standard state

\section{Research Hypotheses Test}

Table 4: Summary of the results of testing research hypotheses

\begin{tabular}{cccc}
\hline hypotheses & Path coefficient & T statistic & Result of hypothesis \\
\hline Hypothesis 1 & $0170 /$ & 0.17 & Not supported \\
Hypothesis 2 & $140 /-$ & -4.35 & supported \\
Hypothesis 3 & $420 /$ & $* * 15.3$ & supported \\
Hypothesis 4 & $520 /$ & $* * 08.5$ & supported \\
Hypothesis 5 & 0.94 & 12.57 & supported \\
\hline
\end{tabular}

Considering the results of testing the hypotheses, relationship between sanction and investment is not significant. In other words, sanction does not influence investment in textile industry. Further, data analyses showed that relationship between investment risk and investment in textile industry is negative. In other words, the higher the risk, the lower the investment in the industry. Moreover, export and import had positive impacts on investment and relationship between investment and employment was positive. This shows that as investment increases, employment (job creation) will also increase.

\section{Conclusion}

The present research aimed to investigate factors which influence investment in textile industry and the influence of development of this industry on Iranian employment rate. Relationship between sanction and investment was not significant. Moreover, the influence of investment risk on investment, export and import on investment and influence of investment on creation of new jobs were significant. The following recommendations are proposed considering the research results:

- Regarding the first hypothesis (sanction): we can turn sanction threats into opportunities for internal producers and take effective steps for exporting textile products in case of proper management.

- Regarding the second hypothesis (risk): if government reduces systematic risk, an appropriate space will be prepared for reducing investment risk in this industry.

- Regarding the third hypothesis (export): effective government solutions for textile industry include reducing taxes, preparation of persuading regulations and preparing the appropriate infrastructure for investment.

- Regarding the fourth hypothesis (import): government can prevent from importing textile products in an unruly manner by receiving appropriate customs duties on textile products.

- Regarding the fifth hypothesis (investment): government can attract internal and external investors by providing political and economic security in business environment. 


\section{References}

Farhang, Manouchehr. Dictionary of economic sciences. Tehran: Alborz Publications, 1992.

Heidarzadeh Hanzaee, Kambiz; Khoshpanjeh, Mahsa \& Rahnama, Afshin., (2011). "Evaluation of the effects of product involvement facets on brand loyalty" African Journal of Business Management Vol. 5(16), pp. 6964-6971.

Johne, Chals P. investment management. Tehran: Negah-e-Danesh, 2005.

Kalantari, Khalil (2009). Structural equations modeling in socio-economic studies, TarhvaManzar advisor engineers, Tehran.

MesbahiMoghadam and Gholam Reza Safari. "investigation of income resulted from risk toleration from Islamic teachings viewpoint." Quarterly of Islamic economy, 2009.

Nahavandiyan, Mohamamd. Familiarity with commercials and economic phrases and definitions.Institute for commercial studies, 1994.

Najafzadeh, Narges. "investigation of factors affecting development of foreign/internal investment in organization of Chabahar free commercial-industrial estate." Master degree thesis (not printed), 2009.

Rahnama, Afshin., Mousavian, Seyed Javad., Alaei, Abbas., Salimi Maghvan, Tavakkol., 2011. "THE SURVEY OF RELATIONSHIP Between Creativity of Staffs and Organizational Effectiveness" Australian Journal of Business and Management Research, Vol.1 No.6 [97-104].

SahiZadehAbiyaneh, Morteza. Completion of textile and dyeing products.Dehkhoda publications, 1996.

ShayanArani, Shahin. "risk management and non-public Islamic Banking", collection of speeches and papers, $12^{\text {th }}$ conference on Islamic Banking, 2001.

Shafaee, Javad., Rahnama, Afshin., Alaei, Abbas., (2012). "Assessing the Impact of Education on Entrepreneurship Characteristics of Students" Journal of Basic and Applied Scientific Research, 2(2), 1451-1460.

Shahsavari, Elham. "investigation of factors affecting investment in industry sector. "master degree thesis, Islamic Azad University, Faculty of Tehran, Central Tehran branch. 2004.

Tavanazadeh, Somayeh., Aligholi, Mansoureh., (2014). "Investigation of Relationship between Service Quality Dimensions and Customers' Satisfaction (case study: Saderat Bank Branches in Tehran City, Iran)" Mediterranean Journal of Social Sciences, Vol 5 No 20, 3116-3120.

Vazifehdoost, Hossein; Vaezi, Maryam \& Tavanazadeh, Somayeh., (2014). "Investigation of the Role of Innovation Dimensions and Knowledge-Based Trust in Accepting Mobile Banking" Journal of Applied Environmental and Biological Sciences Vol 5(2), 106112 